\title{
Inflammaging decreases adaptive and innate immune responses in mice and humans
}

\author{
Daniela Frasca and Bonnie B. Blomberg \\ Department of Microbiology and Immunology, University of Miami Miller School of Medicine, \\ Miami, FL 33101, USA
}

\begin{abstract}
Both the innate and adaptive immune systems decline with age, causing greater susceptibility to infectious diseases and reduced responses to vaccination. Diseases are more severe in elderly than in young individuals and have a greater impact on health outcomes such as morbidity, disability and mortality. Aging is characterized by increased low-grade chronic inflammation, called "inflammaging", measured by circulating levels of TNF-a, IL-6 and CRP, as well as by latent infections with viruses such as cytomegalovirus (CMV). Inflammaging has received considerable attention because it proposes a link between changes in immune cells and a number of diseases and syndromes typical of old age. In this review we aim at summarizing the current knowledge on pathways contributing to inflammaging, on immune responses down-regulated by inflammation and mechanisms proposed. The defects in the immune response of elderly individuals presented in this review should help to discover avenues for effective intervention to promote healthy aging.
\end{abstract}

\author{
Keywords \\ Aging; Immunity; Inflammaging; Vaccine Responses
}

\section{Inflammaging and immunosenescence}

Acute inflammation is a beneficial protective response to harmful conditions such as infections and it is therefore crucial for survival (Franceschi et al. 2007). However, the acute inflammatory response against pathogens is decreased during the aging process, leading to increased susceptibility to infections. Aging is also characterized by a low-grade chronic pro-inflammatory state, called inflammaging (Franceschi et al. 2000), which is a significant risk factor for morbidity and mortality of elderly individuals as it is implicated in the pathogenesis of several disabling diseases of the elderly, such as type-2 diabetes mellitus, osteoporosis, Alzheimer's disease, rheumatoid arthritis, and coronary heart disease (Holmes et al. 2009; Isaacs 2009; Lindholm et al. 2008; Mundy 2007; Sarzi-Puttini et al. 2005). Circulating inflammatory mediators such as cytokines and acute phase proteins, e.g. Creactive protein $(\mathrm{CRP})$ and mannose-binding lectin $(\mathrm{MBL})$, are markers of this low-grade inflammatory status. How inflammaging contributes to adverse health outcomes is largely 
unknown and therefore the identification of pathways controlling inflammaging across multiple systems is important to understand whether interventions designed to reduce inflammaging may be beneficial for the elderly.

\section{Regulation by SNPs}

Increased inflammaging is at least in part genetically determined by polymorphisms in the promoter regions of pro-inflammatory genes. An example is the C/G -174 single nucleotide polymorphisms (SNP) in the promoter of the IL-6 gene which significantly changes serum IL-6 concentrations, with increased IL-6 levels being associated with the GG genotype (Fishman et al. 1998; Giacconi et al. 2004; Olivieri et al. 2002). Elderly men with GG genotype are disadvantaged for longevity due to higher IL-6 serum levels as compared to elderly men with the CG or CC phenotypes (Giacconi et al. 2004) and have a higher risk of death after acute coronary syndrome (Antonicelli et al. 2005). Women with the GG SNP are not as affected as men. Another example is represented by the +874 T/A SNP in the IFN- $\gamma$ gene. In these studies, the $+874 \mathrm{~A}$ allele, which is associated with low IFN $-\gamma$ production, was found positively associated with longevity in male and female centenarians (Lio et al. 2002a; Lio et al. 2002b). This T/A polymorphism coincides with a putative NF-kB binding site, which is involved in the transcription of the human IFN- $\gamma$ gene and therefore directly influences the level of IFN- $\gamma$ (Pravica et al. 2000). Other studies on the -1082 G/A SNP in the anti-inflammatory cytokine IL-10 gene have led to the identification of 3 different inheritable haplotypes, $-1082(\mathrm{G} / \mathrm{A}),-819(\mathrm{C} / \mathrm{T})$ and $-592(\mathrm{C} / \mathrm{A})$ nucleotides in the proximal region of the promoter and shown that the presence of the $-1082 \mathrm{GG}$ genotype, which is associated with high production of the IL-10, was significantly increased in centenarians as compared to adult controls (Lio et al. 2002c). These data altogether suggest that longevity is negatively associated with genotypes coding for pro-inflammatory phenotypes whreas it is positively associated with genotypes coding for anti-inflammatory phenotypes.

\section{Other contributors to inflammaging}

In addition to genetic polymorphisms, other factors have been proposed to drive inflammaging. The major results published on this topic are reported below.

One of the driving forces of inflammaging is believed to be chronic stimulation of immune system cells with viruses such as cytomegalovirus (CMV, the common persistent human $\beta$ herpes virus HHV5). This is accomplished by CMV infecting fibroblasts, epithelial, endothelial, stromal cells, smooth muscle cells (Haspot et al. 2012) which present CMV antigens with MHC class I. Other chronic infections with viruses such as Hepatitis B or C viruses may cause local inflammation, but these infections are mainly localized to the liver and do not contribute significantly to systemic inflammation. The inflammatory response initiated by chronically stimulated innate cells elicits the release of pro-inflammatory cytokines secreted from cells of the innate and the adaptive immune systems and creates a vicious cycle, leading to immune system remodelling. Briefly, CMV induces the production of a variety of pro-inflammatory mediators which in turn induce CMV reactivation (Freeman 2009). In particular, in vitro studies have shown that CMV induces rapid translocation of NF-kB in HeLa cells from the cytoplasm to the nucleus, promoting the 
production of TNF- $a$ which leads to further activation of latent CMV and additional upregulation of the inflammatory response (Prosch et al. 1995).

Other examples of non-infectious agents inducing chronic stimulation of immune cells are macromolecules post-translationally modified (DNA or proteins modified by oxidation, acylation, glycosylation). All these antigens can stimulate cells of the innate immune system to secrete pro-inflammatory mediators and initiate the inflammatory response.

The cellular senescence process could be an additional contributor to the maintenance of inflammaging, due to the acquisition of the senescence-associated secretory phenotype (SASP) by immune cells (Sikora et al. 2011), fibroblasts (Freund et al. 2010) and endothelial cells (Olivieri et al. 2013a), characterized by increased secretion of pro-inflammatory mediators such as cytokines, chemokines, growth factors and proteases (Campisi 2011). The age-dependent accumulation of senescent cells represents a favorable environment for the development of inflammatory-based age-related diseases, including cancer. Several causes of cellular senescence have been proposed, which may be a process to try to reduce cancer, including high proliferation, telomere shortening, DNA mutations, DNA damage, protein aggregation, and production of ROS. All these activate tumor suppressor pathways (p53 and $\mathrm{p} 16^{\mathrm{INK}}$ ) and intracellular signaling through NF-kB, TGF- $\beta$, IL-1, IL-6, CCAAT enhancer binding protein $-\beta$ (C/EBP- $\beta$ ), which leads to irreversible growth arrest, heterochromatin formation and activation of the SASP (reviewed in (Tchkonia et al. 2013).

In tissues, it has been shown that factors secreted by senescent cells can promote tumor development in vivo as well as proliferation and invasiveness in cell culture models. Moreover, the presence of senescent fibroblasts in the proximity of tumor sites may influence tumor-associated macrophages expressing pro-tumoral growth factors (M2) that negatively affect the anti-tumor response by inhibiting tumor-associated dendritic cells, polarization of Th2 responses and induction of T regulatory cells (Davalos et al. 2010; Sica et al. 2006).

Similarly, in the synovial tissue of Rheumatoid Arthritis patients factors secreted by senescent cells, including highly activated T cells, macrophages, NK cells, plasma cells, promote chronic inflammation, responsible for determining the outcome of the local inflammatory process (Brennan et al. 1995; Freund et al. 2010). Fibroblast-like synoviocytes express several molecules that can function as co-stimulatory receptors for senescent CD4+ $\mathrm{T}$ cells, thereby providing fertile ground for the activation of these inflammatory $\mathrm{T}$ cells in the synovium (Goronzy et al. 2005; Goronzy and Weyand 2005; Zhang et al. 2005).

Inflammaging may also be driven by the increase in adiposity with age (Forsythe et al. 2008). Obesity is considered to be an inflammatory predisposition as it is associated with chronic activation of cells of the innate immune system and consequent local and systemic inflammation, responsible for pathologic conditions such as Type-2 Diabetes (T2D) (Hotamisligil 2006; Johnson and Olefsky 2013; Shoelson et al. 2006), cancer (Renehan et al. 2008), psoriasis (Setty et al. 2007), atherosclerosis (Casas et al. 2014), and Inflammatory Bowel Disease (Hass et al. 2006). Adipose tissue inflammation is characterized by infiltration and activation of immune cells that produce cytokines and chemokines that 
contribute to the ongoing chronic inflammation that promotes the degradation of metabolic pathways in obesity. It has been shown that in obesity IFN- $\gamma$-producing CD8+ and Th1 CD4+ T cells infiltrate the visceral adipose tissue (VAT) (Nishimura et al. 2009) and promote secretion of pro-inflammatory cytokines from M1 macrophages which contributes to both local and systemic insulin resistance (Lumeng et al. 2007). In lean individuals, conversely, IL-4/5/13-producing Th2 CD4+ T cells, CD4+ T regulatory (Tregs) and iNKT cells are predominant in the VAT and promote secretion of IL-10 and other antiinflammatory cytokines from M2 macrophages which maintain insulin sensitivity.

Micro-RNAs (miRs), the small non-coding RNAs involved in gene regulation acting mainly at the post-transcriptional level, have recently been proposed as prognostic biomarkers of aging and inflammatory-based and age-associated diseases. The name "inflamma-miRs" has been coined and attributed to those miRs present in the circulation which are up-regulated in aging and increase pro-inflammatory cytokine secretion, acting as agonists of singlestranded RNA-binding TLRs and inducing NF-kB activation (Fabbri et al. 2013; Olivieri et al. 2013a; Olivieri et al. 2013b). Circulating inflamma-miRs may be part of the SASP signature, as they can passively be released by senescent, dead or apoptotic cells and remain in the extracellular space until they are picked up by a distant cell, functioning as mediators of cell-to-cell communication.

Mitochondrial DNA (mtDNA) can be released in the extracellular space and can function as a damage-associated molecular pattern (DAMP) agent causing inflammation (Zhang et al. 2010). Circulating mtDNA levels increase with age and are positively correlated with plasma levels of pro-inflammatory mediators (TNF-a, IL-6, IL-1 receptor antagonist) (Pinti et al. 2014), suggesting a role for mtDNA in the maintenance of the low-grade, chronic inflammation observed in elderly people.

Inflammatory stimuli could also come from the gut microbiota. It has been shown that the microbial composition and diversity of the gut ecosystem of elderly individuals is different from that of younger controls (Heintz and Mair 2014). This altered microbiota composition is associated with increased serum levels of pro-inflammatory mediators such as IL-6 and IL-8 (Biagi et al. 2013; Biagi et al. 2010). In particular, health-promoting bacteria (Bifidobacteria) have been reported to decrease (Mueller et al. 2006; Woodmansey et al. 2004), whereas facultative anaerobes, including Streptococci, Staphylococci, Enterococci and Enterobacteria, increase in the gut with age (Biagi et al. 2010; Rajilic-Stojanovic et al. 2009).

Aging has also been associated with increased intestinal permeability, mainly due to an impaired intestinal epithelial barrier (Meier and Sturm 2009). This increase in permeability allows pro-inflammatory bacterial products to be released in blood contributing to chronic inflammation. This area of research is very important for better understanding diseases typical of old age, such as obesity and metabolic diseases. Moreover, it should be determined if the modulation of the gut microbiome through nutrition may represent an easier way to improve the quality of life in the elderly as compared to standard pharmacological interventions. Recent work has uncovered genes conserved from invertebrates to humans which include the insulin/IGF-1 like signaling pathway, the 
mammalian target of rapamycin (TOR) and AMP-activated protein kinase (AMPK)

(Kenyon 2010). These have been shown to modulate healthy aging in invertebrates and mammals and may be effective targets of intervention to promote longevity.

\section{Aging and inflammation decrease antibody responses in mice and humans}

The age-related increase in inflammation is also contributed to by systemic and local activation of both the innate and adaptive immune systems which have instrinsic functional changes with age. For many years, functional alterations in $\mathrm{T}$ cells have been considered the most significant features of immunosenescence, sufficient per se to explain the age-related decrease in antibody responses to antigens and vaccines observed in elderly individuals. However, a large amount on work has been done more recently showing that defects in other components of the innate and adaptive immune systems also occur with age and contribute to the increased frequency and severity of infectious diseases in the elderly.

\section{Murine T cell defects with age}

In humans, CMV infection and increased inflammation with age has been associated with decreased function (exhaustion) of the CD8 T cell population. Studies on the effects of aging on specific anti-viral responses in mice, although not directly correlating inflammation and $\mathrm{T}$ cell responses, have also shown a significant decrease in percentages and numbers of $\mathrm{CD} 8+\mathrm{T}$ cells specific for at least one of the dominant epitopes of the influenza virus (influenza A nucleoprotein, NP, epitope) (Po et al. 2002).

The cause and effect relationship between lifelong viral infection and $\mathrm{T}$ cell homeostasis and function has been investigated in mice infected with Herpes simplex type I virus (HSV-1), a persistent latent virus (Lang and Nikolich-Zugich 2011). Results have shown that the infection is associated with memory inflation of virus-specific CD8 T cells, similar to the CMV infection in humans. We surmise wuold be due to increased inflammation as it is in humans. When the authors investigated if and how these inflated memory cells were maintained from adulthood into old age, no significant differences in the numbers, ex vivo antigen-specific IFN- $\gamma$ production and in vivo recall response were found between young and old memory $\mathrm{T}$ cells. There was a discrete shift from effector memory phenotype in young mice to central memory phenotype in old mice, with fewer cells from old mice expressing the killer cell lectin-like receptor G1 (KLRG1).

Moreover, when young mice were systemically infected with HSV-1, murine (M) CMV, or both viruses and then infected with the recombinant Listeria monocytogenes expressing the OVA surrogate antigen (Lm-OVA) (Smithey et al. 2012) it was found that mice with lifelong HSV-1 infections showed impaired bacterial control, impaired CD8 T cell function, as compared to age-matched non infected controls. An increase in all-cause mortality in mice carrying latent MCMV or HSV-1, was shown. MCMV in these experiments did not lead to global numerical loss of phenotypically defined naive $\mathrm{T}$ cells, but only to reduction of virus-specific precursors.

Similar experiments were performed to test the effects of latent CMV infection on antibody responses (Marandu et al. 2014). In these experiments, young mice were infected with 
MCMV and challenged with Vesicular Stomatitis virus (VSV) later in life, at the age of 15-18 months. Results indicated that latent infection with MCMV resulted in diminished neutralizing titers of specific serum IgG at day 7 post challenge, did not alter significantly the size of the blood memory B cell compartment, and increased the size of the effector memory CD4 $\mathrm{T}$ cell subset, suggesting that the delayed antibody class switch was an intrinsic defect of the B cells and unlikely deriving from defects in $\mathrm{T}$ cell help. To explain these results, the authors have proposed that CMV may impair B cell responses either indirectly by disrupting the lymph-node architecture and thus the signaling network that is necessary for the germinal center reaction, or directly by affecting B cell class switch machinery and/or up-regulating TNFa signaling which has been shown to impact B cell functions (see below).

Studies linking inflammation and murine antibody responses have shown that vaccine efficacy is lower in inflammatory conditions such as obesity. In particular, it has been demonstrated that mice fed a high fat diet (HFD) had lower levels of neutralizing antibody titers, higher serum levels of the monocyte chemotactic protein MCP-1 and lower percentages of influenza virus-specific effector memory CD8+ T cells, as compared to control mice. Moreover, after challenge with influenza virus, the lungs of HFD mice showed more severe inflammatory responses as compared with the lungs of control mice, even after vaccination, suggesting that the inflammatory condition in obesity may contribute to the suppressed efficacy of influenza vaccination (Park et al. 2014).

\section{Human T cell defects with age}

Studies in humans have shown that the reduced response to vaccination in the elderly is correlated with the well-known decrease in T cell functions (Goronzy et al. 2001; Kovaiou et al. 2007; Saurwein-Teissl et al. 2002), in particular a reduction in naïve T cells and a concomitant increase in memory/effector T cells (Pawelec et al. 2002), loss in CD28 expression (Vallejo 2005), and increased CMV seropositivity (Pawelec et al. 2009). The irreversible loss of $\mathrm{CD} 28$ expression due to chronic immune activation of human $\mathrm{T}$ lymphocytes in long term culture is one of the signatures of replicative senescence (Vallejo et al. 2004) and even in young individuals this has been associated with persistent infections, autoimmune and inflammatory conditions (Lewis et al. 1999; Martinez-Taboada et al. 1996; Neil et al. 1994; Schmidt et al. 1996). Although aging is associated in general with increased inflammation, increases in the anti-inflammatory response can also occur, characterized by IL-10 production and decreased IFN- $\gamma$ :IL-10 ratio and in influenza-stimulated lymphocytes has been shown to be associated with reduced cytolytic capacity of CD8+ T cells which clear influenza virus from infected lungs (McElhaney et al. 2012).

The decreased protective effect of vaccination in elderly people has been associated with the presence of CMV latency (Kovaiou et al. 2007; Olsson et al. 2000; Pawelec et al. 2009). In a recent report, $\mathrm{CMV}$-seropositivity was associated with a lower response rate (serum antibodies) to the influenza vaccine in individuals 260 years of age (Derhovanessian et al. 2013b). Unlike reported data, late-differentiated (CD45RA+CCR7-CD27-CD28-) CD4+, but not $\mathrm{CD} 8+$, $\mathrm{T}$ cells were associated with poorer vaccine responses, suggesting that latent CMV infection has a deleterious effect on influenza antibody responses in the elderly, which 
might be mediated by CD4 T cells with an exhausted phenotype (i.e. lacking CCR7, CD27, CD28 markers and reexpressing the CD45RA marker). The same group has recently demonstrated that CD4 responses to influenza core proteins are absent in half of the CMVseropositive elderly, but present in those not infected with CMV, which respond as well as young individuals, suggesting that advanced chronological age plays a role in reducing the CD4 responses to influenza but only in concert with CMV infection (Derhovanessian et al. 2014). The induction of terminally differentiated $T$ cells, and consequent accumulation of senescent T cells (Derhovanessian et al. 2013b; Trzonkowski et al. 2003), upregulate IL-10 production (McElhaney et al. 2012). IL-10 suppresses CTL responses and down-regulates the expression of costimulatory molecules on antigen-presenting cells (van Duin et al. 2007a), and together with the down-regulation of IFN- $\gamma$ production leads to reduced stimulation of $\mathrm{T}$ cell memory and poorer responses to influenza vaccination in elderly individuals (Derhovanessian et al. 2009; McElhaney et al. 2012). However, the widely accepted assumption that more late-differentiated $\mathrm{T}$ cells are detrimental to survival may not necessarily be true, at least in the very elderly, i.e $\geq 85$ years of age. Rather, as documented in a recent publication from this group, the presence of larger proportions of latedifferentiated effector memory and effector cells, specific for previously encountered CMV antigens, correlates with the ability to mount robust pro-inflammatory responses against major CMV antigens and is therefore positively associated with longer survival in this very old population, meaning that at least some of this population are functional and necessary for further protection to subsequent infection (Derhovanessian et al. 2013a).

Another study has also shown that the lack of antibody production following influenza vaccination with the Trivalent Inactivated Vaccine is associated with increased frequency of expanded CD8+CD28-T cell clones. These clones express effector cell markers and are mostly CD45RA+. When isolated and put into culture, they are unable to proliferate, but produce IFN- $\gamma$ upon stimulation with anti-CD3 or an autoantigen, which might be the basis for a change in the polarization of the immune system in elderly persons and the development of age-related immune deficiencies (Saurwein-Teissl et al. 2002). Others have confirmed and extended these results showing that the frequencies of CD8+CD28-T cells can be useful biological markers of compromised immune competence, identifying individuals at risk for insufficient antibody responses (Goronzy et al. 2001).

Terminally differentiated senescent human CD27-CD28-CD4+ T cells utilize an intracellular signaling pathway for the activation of the p38 MAPK that senses changes in intracellular levels of glucose as well as genotoxic stress and spontaneously engages the metabolic master regulator AMPK to trigger autophosphorylation of p38. Signaling through this pathway inhibits telomerase activity, $\mathrm{T}$ cell proliferation and the expression of key components of the TCR signaling machinery (Lanna et al. 2014). These results are in line with the hypothesis that aging is powerfully influenced by alterations in nutrient sensing and metabolism (Johnson et al. 2013). Whether similar pathways associated with senescence are also utilized in other terminally differentiated immune cell types is currently under investigation in different laboratories. 


\section{Mouse and human B cell defects with age}

Our laboratory has shown that in humans, age-related intrinsic B cell defects also occur in blood and these contribute to decreased vaccine response. These include decreases in class switch recombination (CSR), the process that generates protective antibodies and memory B cells; decreases in the expression of the enzyme, activation-induced cytidine deaminase (AID), the transcription factor E47, which contributes to AID regulation; and decreased percentages of switched memory B cells (CD19+CD27+IgD-) before and after vaccination as compared with younger individuals.

In the last 5 influenza vaccine seasons, we have measured the antibody response to the seasonal and pandemic vaccines in serum and we have associated this response with the $\mathrm{B}$ cell response after vaccination to the vaccine in vitro. In vivo and in vitro B cell responses have been measured respectively by the hemagglutination inhibition assay (HAI) and by AID mRNA expression by qPCR after B cell restimuation with the vaccine (or stimulation to $\mathrm{CpG}$ ). AID is a measure of CSR and of B cell function which we have previously established to reflect the generation of specific IgG and associate with other mechanistic markers such as E47 (Frasca et al. 2007) which transcriptionally activates AID (Sayegh et al. 2003). Our published results have shown that the specific response of $B$ cells to vaccination in vivo and in vitro are both decreased with age and are significantly correlated (Frasca et al. 2010; Frasca et al. 2012a; Khurana et al. 2012). These results support our hypothesis that the in vitro AID response recapitulates what has occurred in vivo in the germinal center in the generation of memory B cells. Moreover, switched memory B cell percentages and $\mathrm{CpG}$-induced AID before vaccination are both good $\mathrm{B}$ cell biomarkers that are reduced in elderly as compared to young individuals and are significantly correlated with the in vivo antibody response to the vaccine (Frasca et al. 2010; Frasca et al. 2012a). Therefore, we have proposed them as good predictive biomarkers for response to vaccines and infectious agents in humans (Frasca et al. 2010; Frasca et al. 2012a).

More recently, we have measured the influenza vaccine response in young and elderly patients with T2D (Frasca et al. 2013). T2D is a metabolic, inflammatory disease not associated with autoimmunity, but often characterized by obesity, hypertension, dyslipidemia, accelerated atherosclerosis and increased mortality (Alberti and Zimmet 1998; Nikolajczyk 2010). We found that the in vivo responses, as well as B cell-specific markers identified above, decrease by age in healthy individuals but not in T2D patients, despite high levels of B cell-intrinsic inflammation measured by intracellular TNF-a in T2D patients. This was surprising to us as we had previously demonstrated that B cell-intrinsic inflammation negatively impacts B cell function in mice (Frasca et al. 2012b) and humans (Frasca et al. 2014). Previous studies, designed to evaluate the effect of T2D on influenza vaccine-specific $\mathrm{T}$ cell responses, have shown controversial results, as these responses can be either affected (Pozzilli et al. 1986) or not (McElhaney et al. 1996) by the disease. We hypothesized that the optimal response of T2D patients to the influenza vaccine may be due to the fact that the innate immune system of T2D patients is beneficially hyper-activated, as we found elevated serum levels of bacterial lipopolysaccharide (LPS) and soluble CD14, and we suggest that these may not only counteract the negative effects of inflammation from increased TNF-a, IL-6 and CRP, but also induce a direct stimulation of B cells. Another 
explanation for these data is that the T2D patients in our study were all taking Metformin, the anti-inflammatory drug known to block TNF-a signaling in all cells, including B cells.

We have recently demonstrated for the first time a negative association between CMVseropositivity and the $\mathrm{B}$ cell predictive biomarkers of optimal vaccine responses previously characterized in our laboratory (Frasca et al., Vaccine, in press). We found CMVseropositivity associated with increased levels of systemic and B cell-intrinsic inflammation and this may be one of the mechanisms through which CMV down-regulates antibody responses (see below). TNF-a is a powerful stimulator of the promoter/enhancer of the human CMV virus leading to further up-regulation and exacerbation of the systemic inflammatory response (Prosch et al. 1995). This positive feedback loop drives inflammaging more effectively in elderly as compared to young individuals, causing deleterious effects in the immune system of the individual. Additional mechanisms may be the ones described above: accumulation of terminally differentiated T cells, up-regulated IL-10 production, down-regulated IFN- $\gamma$ production and CTL responses.

Results from our studies showing age effects on mouse and human B cells are summarized in Fig. 1.

\section{Defects with age in mouse and human monocytes/macrophages and dendritic cells}

In mice, age-related alterations in macrophage numbers and function have been reported and associated with enhanced susceptibility to infection (Brubaker et al. 2011). In response to LPS stimulation, splenic macrophages from old mice produced less pro-inflammatory cytokines (TNF-a, IL-1 $\beta$, IL-6, IL-12) as compared to young mice (Gomez et al. 2006; Linton and Dorshkind 2004; Murciano et al. 2008; Ren et al. 2009) and this has been attributed to the increased levels of circulating pro-inflammatory cytokines which induce a pre-activation statuts of the macrophages and consequent down-regulation of their function (Kovacs et al. 2002). The reduced function of macrophages from old mice may be dependent from reduced expression of Toll-like receptors (TLRs) which has been reported in both splenic and peritoneal macrophages of aged C57/BL6 mice and includes all TLRs (TLR1-9) (Murciano et al. 2008; Renshaw et al. 2002), reduced activation of nuclear factor kappa B (NF- $\mathrm{B}$ ) and mitogen-activated protein kinase (MAPK) (Boehmer et al. 2004; Renshaw et al. 2002; van Duin et al. 2007b), increased levels of the signalling protein A20 (Hinojosa et al. 2014), a ubiquitin-editing enzyme that blocks TRAF6 signaling through disruption of the ubiquitin complexes attached to TRAF6 (Shembade et al. 2010).

Defects in cytokine production by DCs from elderly individuals have also been strongly associated with poor antibody production in response to the influenza vaccine, due to a functional impairment in TLR function in the aging innate cells (Panda et al. 2010). It was found that both myeloid DCs (mDCs) and plasmacytoid DCs (pDCs) from elderly individuals were significantly impaired in their capacity to secrete TNF-a/IL-6/IL-12 (p40) and in TNF-a/IFN-a production, respectively, in response to TLR1/2, TLR2/6, TLR3, TLR5, and TLR8 engagement by mDCs and TLR7 and TLR9 by pDCs. These defects were strongly associated with poor antibody response to the influenza vaccine. 
When monocytes from young and elderly individuals were evaluated before and after influenza vaccination, it was found that CD14+CD16+ inflammatory monocytes were induced after vaccination in young and to a lesser extent in elderly individuals and TNF-a/ IL-6 production was strongly associated with influenza vaccine antibody response (Mohanty et al. 2014). Conversely, levels of the anti-inflammatory cytokine IL-10 were higher in inflammatory monocytes from elderly as compared to young individuals before and after vaccination and negatively correlated with the in vivo response, providing for the first time evidence of the involvement of dysregulated IL-10 production vaccine responses in the elderly.

\section{Inflammaging induces intrinsic inflammation in immune cells and down- regulates their responses in mice and humans}

The inflammatory status of the animal/individual may impact the function of cells of the immune system. It has been shown that human serum TNF-a levels negatively correlate with T cell function (Bryl et al. 2005; Bryl et al. 2001; Parish et al. 2009). In particular, in Rheumatoid Arthritis patients, characterized by high systemic inflammation and TNF-a levels, these may contribute to the down-regulation of CD28 expression on T cells, as antiTNF-a therapy is associated with the restoration of the CD28+ T cell populations within the diseased joints (Bryl et al. 2005). Longitudinal analysis of CD8+ T lymphocytes that reached replicative senescence in culture in response to multiple rounds of antigen-driven proliferation showed that the loss of $\mathrm{CD} 28$ expression parallels the progressive increase in TNF-a secretion (Effros et al. 2005). Inhibition of TNF-a with anti-TNF-a or using a TNFa receptor inhibitor delays the loss of CD28 expression and the multiple functional changes associated with CD8 T cell replicative senescence (Parish et al. 2009).

B cells are also affected by inflammation. B cells themselves express innate immune receptors which recognize exogenous pathogens or the adjuvants used to induce an immune response. B cells can either promote immune responses by acting as antigen-presenting cells or they can regulate immune responses by secreting immunoregulatory cytokines. Published data have shown that B cells from mice infected with Toxoplasma gondii, Heligomosomoides polygyrus or Pneumocystis carinii can secrete pro-inflammatory cytokines such as TNF-a (Lund et al. 2006; Menard et al. 2007; Wojciechowski et al. 2009).

Data from our laboratory (Frasca et al. 2012b) have shown that unstimulated splenic B cells from old mice make more TNF-a than those from young mice. We have hypothesize that this "pre-activated" phenotype of the old B cells renders them refractory to further stimulation, i.e. old B cells are less efficient than young B cells in undergoing CSR upon in vitro stimulation, and we would argue in vivo stimulation, with antigen or mitogens. To confirm the hypothesis that TNF-a inhibits subsequent CSR signals, we pre-incubated splenic B cells with exogenous TNF-a before antigen/mitogen stimulation and found that this pre-treatment significantly decreases both young and old B cell responses. Conversely, blocking TNF-a by adding an anti-TNF- $a$ antibody to B cells before stimulation significantly somewhat increases CSR in young and more significantly restores it to young levels in old cultured B cells. We have used these data to propose a molecular mechanism for TNF-a-mediated down-regulation of CSR in old B cells. 
More recently, we have shown that, similar to mouse B cells, human unstimulated B cells from elderly individuals also make significantly higher levels of TNF- $a$ than those from young subjects, and this is positively correlated with serum TNF- $a$. These both correlate negatively with in vitro B cell function, measured by AID (Frasca et al. 2014; Frasca et al. 2013). The levels of systemic as well as intracellular TNF-a in B cells are increased in CMV-positive individuals, either young or old (Frasca et al., Vaccine, in press). An antiTNF- $\alpha$ antibody significantly increases the response in old cultured B cells, providing a proof of principle that it is possible to improve class switch in elderly individuals by counteracting autocrine TNF-a (Frasca et al. 2014). These findings may help to explain the reduced antibody response of elderly individuals to antigens and vaccines and also provide biomarkers for good responsiveness and crucial targets for development of more effective vaccines. Results from this study indeed identify TNF-a as another B cell-specific biomarker, which can help to predict the quality of in vivo and in vitro B cell responses. Moreover, the possibility to control inflammaging represents a powerful tool to modulate and counteract the major age-related pathologies in order to target therapeutic interventions and improve health status of the elderly population.

Cytokine production by B cells is a field of increasing interest in aging and in age-associated diseases. Our results highlight the differential contribution of B cell subsets to inflammaging. We hypothesize that naïve and memory B cells are programmed to play different roles in the regulation of the immune response, as they release different effector cytokines either before or after stimulation. The fact that only memory B cells make TNF- $\alpha$ suggests a switch in the cytokine program of B cells transitioning from the naïve to the memory phenotype. Moreover, the major memory subset is the IgM memory and the percentage of this population is maintained (Frasca and Blomberg 2011; Frasca et al. 2011; Shi et al. 2005) during aging, suggesting that this subset significantly contributes to the inflammatory profile of B cells. As for naïve B cells, they have been shown to make the regulatory cytokine IL-10 (Duddy et al. 2007).

\section{Summary}

Inflammation leads to decreased immune responses with age. Various factors contribute to this, including polymorphisms in the promoter regions of pro-inflammatory genes, chronic stimulation of immune cells with viruses such as CMV, cellular senescence, obesity, changes in the gut microbiome as well as increased permeability from the intestine. All these factors are causing defects in components of the innate and adaptive immune systems leading to increased frequency and severity of infectious diseases in the elderly. The defects presented in this review should allow the discovery of mechanisms for improvement of immune responses in elderly individuals in the near future.

\section{Acknowledgements}

This study was supported by NIH AG-32576 and AG023717 grants to BBB and by NIH AI096446 and AG042826 grants to $\mathrm{BBB}$ and $\mathrm{DF}$. 


\section{References}

Alberti KG, Zimmet PZ. Definition, diagnosis and classification of diabetes mellitus and its complications. Part 1: diagnosis and classification of diabetes mellitus provisional report of a WHO consultation. Diabet Med. 1998; 15:539-553. doi:10.1002/ (SICI)1096-9136(199807)15:7<539::AID-DIA668>3.0.CO;2-S. [PubMed: 9686693]

Antonicelli R, et al. The interleukin-6 -174 G>C promoter polymorphism is associated with a higher risk of death after an acute coronary syndrome in male elderly patients. International journal of cardiology. 2005; 103:266-271. doi:10.1016/j.ijcard.2004.08.064. [PubMed: 16098388]

Biagi E, Candela M, Turroni S, Garagnani P, Franceschi C, Brigidi P. Ageing and gut microbes: perspectives for health maintenance and longevity. Pharmacol Res. 2013; 69:11-20. doi:10.1016/ j.phrs.2012.10.005. [PubMed: 23079287]

Biagi E, et al. Through ageing, and beyond: gut microbiota and inflammatory status in seniors and centenarians. PloS one. 2010; 5:e10667. doi:10.1371/journal.pone.0010667. [PubMed: 20498852]

Boehmer ED, Goral J, Faunce DE, Kovacs EJ. Age-dependent decrease in Toll-like receptor 4mediated proinflammatory cytokine production and mitogen-activated protein kinase expression. Journal of leukocyte biology. 2004; 75:342-349. doi:10.1189/jlb.0803389. [PubMed: 14634059]

Brennan FM, Gibbons DL, Cope AP, Katsikis P, Maini RN, Feldmann M. TNF inhibitors are produced spontaneously by rheumatoid and osteoarthritic synovial joint cell cultures: evidence of feedback control of TNF action. Scandinavian journal of immunology. 1995; 42:158-165. [PubMed: 7631138]

Brubaker AL, Palmer JL, Kovacs EJ. Age-related Dysregulation of Inflammation and Innate Immunity: Lessons Learned from Rodent Models. Aging and disease. 2011; 2:346-360. [PubMed: 22396887]

Bryl E, Vallejo AN, Matteson EL, Witkowski JM, Weyand CM, Goronzy JJ. Modulation of CD28 expression with anti-tumor necrosis factor alpha therapy in rheumatoid arthritis. Arthritis and rheumatism. 2005; 52:2996-3003. doi:10.1002/art.21353. [PubMed: 16200579]

Bryl E, Vallejo AN, Weyand CM, Goronzy JJ. Down-regulation of CD28 expression by TNF-alpha. Journal of immunology. 2001; 167:3231-3238.

Campisi J. Cellular senescence: putting the paradoxes in perspective. Current opinion in genetics \& development. 2011; 21:107-112. doi:10.1016/j.gde.2010.10.005. [PubMed: 21093253]

Casas R, Sacanella E, Estruch R. The immune protective effect of the Mediterranean diet against chronic low-grade inflammatory diseases. Endocrine, metabolic \& immune disorders drug targets. 2014; 14:245-254.

Davalos AR, Coppe JP, Campisi J, Desprez PY. Senescent cells as a source of inflammatory factors for tumor progression. Cancer metastasis reviews. 2010; 29:273-283. doi:10.1007/ s10555-010-9220-9. [PubMed: 20390322]

Derhovanessian E, Larbi A, Pawelec G. Biomarkers of human immunosenescence: impact of Cytomegalovirus infection. Curr Opin Immunol. 2009; 21:440-445. doi:S0952-7915(09)00091-0 [pii] 10.1016/j.coi.2009.05.012. [PubMed: 19535233]

Derhovanessian E, Maier AB, Hahnel K, McElhaney JE, Slagboom EP, Pawelec G. Latent infection with cytomegalovirus is associated with poor memory CD4 responses to influenza A core proteins in the elderly. Journal of immunology. 2014; 193:3624-3631. doi:10.4049/jimmunol.1303361.

Derhovanessian E, et al. Lower proportion of naive peripheral CD8+ T cells and an unopposed proinflammatory response to human. Cytomegalovirus proteins in vitro are associated with longer survival in very elderly people Age. 2013a; 35:1387-1399. doi:10.1007/s11357-012-9425-7. [PubMed: 22661297]

Derhovanessian E, Theeten H, Hahnel K, Van Damme P, Cools N, Pawelec G. Cytomegalovirusassociated accumulation of late-differentiated CD4 T-cells correlates with poor humoral response to influenza vaccination. Vaccine. 2013b; 31:685-690. doi:10.1016/j.vaccine.2012.11.041. [PubMed: 23196209]

Duddy M, et al. Distinct effector cytokine profiles of memory and naive human B cell subsets and implication in multiple sclerosis. Journal of immunology. 2007; 178:6092-6099. doi:178/10/6092 [pii]. 
Effros RB, Dagarag M, Spaulding C, Man J. The role of CD8+ T-cell replicative senescence in human aging. Immunological reviews. 2005; 205:147-157. doi:10.1111/j.0105-2896.2005.00259.x. [PubMed: 15882351]

Fabbri M, Paone A, Calore F, Galli R, Croce CM. A new role for microRNAs, as ligands of Toll-like receptors. RNA biology. 2013; 10:169-174. doi:10.4161/rna.23144. [PubMed: 23296026]

Fishman D, Faulds G, Jeffery R, Mohamed-Ali V, Yudkin JS, Humphries S, Woo P. The effect of novel polymorphisms in the interleukin-6 (IL-6) gene on IL-6 transcription and plasma IL-6 levels, and an association with systemic-onset juvenile chronic arthritis. The Journal of clinical investigation. 1998; 102:1369-1376. doi:10.1172/JCI2629. [PubMed: 9769329]

Forsythe LK, Wallace JM, Livingstone MB. Obesity and inflammation: the effects of weight loss. Nutrition research reviews. 2008; 21:117-133. doi:10.1017/S0954422408138732. [PubMed: 19087366]

Franceschi C, Bonafe M, Valensin S, Olivieri F, De Luca M, Ottaviani E, De Benedictis G. Inflammaging. An evolutionary perspective on immunosenescence. Annals of the New York Academy of Sciences. 2000; 908:244-254. [PubMed: 10911963]

Franceschi C, et al. Inflammaging and anti-inflammaging: a systemic perspective on aging and longevity emerged from studies in humans. Mechanisms of ageing and development. 2007; 128:92-105. doi:S0047-6374(06)00249-1 [pii] 10.1016/j.mad.2006.11.016. [PubMed: 17116321]

Frasca D, Blomberg BB. Aging affects human B cell responses. J Clin Immunol. 2011; 31:430-435. doi:10.1007/s10875-010-9501-7. [PubMed: 21318330]

Frasca D, Diaz A, Romero M, Landin AM, Blomberg BB. Age effects on B cells and humoral immunity in humans. Ageing research reviews. 2011; 10:330-335. doi:S1568-1637(10)00061-9 [pii] 10.1016/j.arr.2010.08.004. [PubMed: 20728581]

Frasca D, Diaz A, Romero M, Landin AM, Blomberg BB. High TNF-alpha levels in resting B cells negatively correlate with their response. Experimental gerontology. 2014; 54:116-122. doi: 10.1016/j.exger.2014.01.004. [PubMed: 24440385]

Frasca D, et al. Intrinsic defects in B cell response to seasonal influenza vaccination in elderly humans. Vaccine. 2010; 28:8077-8084. doi:S0264-410X(10)01492-1 [pii] 10.1016/j.vaccine.2010.10.023. [PubMed: 20974306]

Frasca D, Diaz A, Romero M, Mendez NV, Landin AM, Ryan JG, Blomberg BB. Young and elderly patients with type 2 diabetes have optimal B cell responses to the seasonal influenza vaccine. Vaccine. 2013 doi:10.1016/j.vaccine.2013.05.003.

Frasca D, Diaz A, Romero M, Phillips M, Mendez NV, Landin AM, Blomberg BB. Unique biomarkers for B-cell function predict the serum response to pandemic H1N1 influenza vaccine. Int Immunol. 2012a; 24:175-182. doi:dxr123 [pii] 10.1093/intimm/dxr123. [PubMed: 22281510]

Frasca D, Landin AM, Alvarez JP, Blackshear PJ, Riley RL, Blomberg BB. Tristetraprolin, a negative regulator of mRNA stability, is increased in old B cells and is involved in the degradation of E47 mRNA. Journal of immunology. 2007; 179:918-927.

Frasca D, et al. A molecular mechanism for TNF-alpha-mediated downregulation of B cell responses. Journal of immunology. 2012b; 188:279-286. doi:jimmunol.1003964 [pii] 10.4049/jimmunol. 1003964.

Freeman RB Jr. The 'indirect' effects of cytomegalovirus infection. Am J Transplant. 2009; 9:24532458. doi:10.1111/j.1600-6143.2009.02824.x. [PubMed: 19843027]

Freund A, Orjalo AV, Desprez PY, Campisi J. Inflammatory networks during cellular senescence: causes and consequences. Trends in molecular medicine. 2010; 16:238-246. doi:10.1016/ j.molmed.2010.03.003. [PubMed: 20444648]

Giacconi R, et al. The -174G/C polymorphism of IL-6 is useful to screen old subjects at risk for atherosclerosis or to reach successful ageing. Experimental gerontology. 2004; 39:621-628. doi: 10.1016/j.exger.2003.12.013. [PubMed: 15050298]

Gomez CR, Goral J, Ramirez L, Kopf M, Kovacs EJ. Aberrant acute-phase response in aged interleukin-6 knockout mice. Shock. 2006; 25:581-585. doi:10.1097/01.shk.000029553.39081.ec. [PubMed: 16721265]

Goronzy JJ, Fulbright JW, Crowson CS, Poland GA, O'Fallon WM, Weyand CM. Value of immunological markers in predicting responsiveness to influenza vaccination in elderly 
individuals. Journal of virology. 2001; 75:12182-12187. doi:10.1128/JVI.

75.24.12182-12187.2001. [PubMed: 11711609]

Goronzy JJ, Henel G, Sawai H, Singh K, Lee EB, Pryshchep S, Weyand CM. Costimulatory pathways in rheumatoid synovitis and T-cell senescence. Annals of the New York Academy of Sciences. 2005; 1062:182-194. doi:10.1196/annals.1358.022. [PubMed: 16461801]

Goronzy JJ, Weyand CM. Rheumatoid arthritis. Immunological reviews. 2005; 204:55-73. doi: 10.1111/j.0105-2896.2005.00245.x. [PubMed: 15790350]

Haspot F, et al. Human cytomegalovirus entry into dendritic cells occurs via a macropinocytosis-like pathway in a pH-independent and cholesterol-dependent manner. PloS one. 2012; 7:e34795. doi: 10.1371/journal.pone.0034795. [PubMed: 22496863]

Hass DJ, Brensinger CM, Lewis JD, Lichtenstein GR. The impact of increased body mass index on the clinical course of Crohn's disease. Clinical gastroenterology and hepatology : the official clinical practice journal of the American Gastroenterological Association. 2006; 4:482-488. doi:10.1016/ j.cgh.2005.12.015. [PubMed: 16616354]

Heintz C, Mair W. You are what you host: microbiome modulation of the aging process. Cell. 2014; 156:408-411. doi:10.1016/j.cell.2014.01.025. [PubMed: 24485451]

Hinojosa CA, Akula Suresh Babu R, Rahman MM, Fernandes G, Boyd AR, Orihuela CJ. Elevated A20 contributes to age-dependent macrophage dysfunction in the lungs. Experimental gerontology. 2014; 54:58-66. doi:10.1016/j.exger.2014.01.007. [PubMed: 24440463]

Holmes C, et al. Systemic inflammation and disease progression in Alzheimer disease. Neurology. 2009; 73:768-774. doi:73/10/768 [pii] 10.1212/WNL.0b013e3181b6bb95. [PubMed: 19738171]

Hotamisligil GS. Inflammation and metabolic disorders. Nature. 2006; 444:860-867. doi:10.1038/ nature05485. [PubMed: 17167474]

Isaacs JD. Therapeutic agents for patients with rheumatoid arthritis and an inadequate response to tumour necrosis factor-alpha antagonists. Expert Opin Biol Ther. 2009; 9:1463-1475. doi: 10.1517/14712590903379494. [PubMed: 19916731]

Johnson AM, Olefsky JM. The origins and drivers of insulin resistance. Cell. 2013; 152:673-684. doi: 10.1016/j.cell.2013.01.041. [PubMed: 23415219]

Johnson SC, Rabinovitch PS, Kaeberlein M. mTOR is a key modulator of ageing and age-related disease. Nature. 2013; 493:338-345. doi:10.1038/nature11861. [PubMed: 23325216]

Kenyon CJ. The genetics of ageing. Nature. 2010; 464:504-512. doi:10.1038/nature08980. [PubMed: 20336132]

Khurana S, Frasca D, Blomberg B, Golding H. AID activity in B cells strongly correlates with polyclonal antibody affinity maturation in-vivo following pandemic 2009-H1N1 vaccination in humans. PLoS Pathog. 2012; 8:e1002920. doi:10.1371/journal.ppat.1002920. [PubMed: 23028320]

Kovacs EJ, Grabowski KA, Duffner LA, Plackett TP, Gregory MS. Survival and cell mediated immunity after burn injury in aged mice. Journal of the American Aging Association. 2002; 25:39. doi:10.1007/s11357-002-0001-4. [PubMed: 23604885]

Kovaiou RD, Herndler-Brandstetter D, Grubeck-Loebenstein B. Age-related changes in immunity: implications for vaccination in the elderly. Expert reviews in molecular medicine. 2007; 9:1-17. doi:10.1017/S1462399407000221. [PubMed: 17266794]

Lang A, Nikolich-Zugich J. Functional CD8 T cell memory responding to persistent latent infection is maintained for life. Journal of immunology. 2011; 187:3759-3768. doi:10.4049/jimmunol. 1100666.

Lanna A, Henson SM, Escors D, Akbar AN. The kinase p38 activated by the metabolic regulator AMPK and scaffold TAB1 drives the senescence of human T cells. Nature immunology. 2014; 15:965-972. doi:10.1038/ni.2981. [PubMed: 25151490]

Lewis DE, Yang L, Luo W, Wang X, Rodgers JR. HIV-specific cytotoxic T lymphocyte precursors exist in a CD28-CD8+ T cell subset and increase with loss of CD4 T cells. Aids. 1999; 13:10291033. [PubMed: 10397532]

Lindholm E, Bakhtadze E, Cilio C, Agardh E, Groop L, Agardh CD. Association between LTA, TNF and AGER polymorphisms and late diabetic complications. PLoS One. 2008; 3:e2546. doi: 10.1371/journal.pone.0002546. [PubMed: 18575614] 
Linton PJ, Dorshkind K. Age-related changes in lymphocyte development and function. Nature immunology. 2004; 5:133-139. doi:10.1038/ni1033. [PubMed: 14749784]

Lio D, et al. Genotype frequencies of the +874T-->A single nucleotide polymorphism in the first intron of the interferon-gamma gene in a sample of Sicilian patients affected by tuberculosis. European journal of immunogenetics : official journal of the British Society for Histocompatibility and Immunogenetics. 2002a; 29:371-374. [PubMed: 12358843]

Lio D, et al. Allele frequencies of $+874 \mathrm{~T}-->$ A single nucleotide polymorphism at the first intron of interferon-gamma gene in a group of Italian centenarians. Experimental gerontology. 2002b; 37:315-319. [PubMed: 11772518]

Lio D, et al. Gender-specific association between -1082 IL-10 promoter polymorphism and longevity. Genes and immunity. 2002c; 3:30-33. doi:10.1038/sj.gene.6363827. [PubMed: 11857058]

Lumeng CN, Bodzin JL, Saltiel AR. Obesity induces a phenotypic switch in adipose tissue macrophage polarization. The Journal of clinical investigation. 2007; 117:175-184. doi:10.1172/ JCI29881. [PubMed: 17200717]

Lund FE, Hollifield M, Schuer K, Lines JL, Randall TD, Garvy BA. B cells are required for generation of protective effector and memory CD4 cells in response to Pneumocystis lung infection. Journal of immunology. 2006; 176:6147-6154. doi:176/10/6147 [pii].

Marandu TF, Finsterbusch K, Kroger A, Cicin-Sain L. Mouse CMV infection delays antibody class switch upon an unrelated virus challenge. Experimental gerontology. 2014; 54:101-108. doi: 10.1016/j.exger.2014.01.017. [PubMed: 24462805]

Martinez-Taboada VM, Goronzy JJ, Weyand CM. Clonally expanded CD8 T cells in patients with polymyalgia rheumatica and giant cell arteritis. Clinical immunology and immunopathology. 1996; 79:263-270. [PubMed: 8635285]

McElhaney JE, Pinkoski MJ, Au D, Lechelt KE, Bleackley RC, Meneilly GS. Helper and cytotoxic T lymphocyte responses to influenza vaccination in healthy compared to diabetic elderly. Vaccine. 1996; 14:539-544. [PubMed: 8782353]

McElhaney JE, Zhou X, Talbot HK, Soethout E, Bleackley RC, Granville DJ, Pawelec G. The unmet need in the elderly: how immunosenescence, CMV infection, co-morbidities and frailty are a challenge for the development of more effective influenza vaccines. Vaccine. 2012; 30:20602067. doi:10.1016/j.vaccine.2012.01.015. [PubMed: 22289511]

Meier J, Sturm A. The intestinal epithelial barrier: does it become impaired with age? Digestive diseases. 2009; 27:240-245. doi:10.1159/000228556. [PubMed: 19786747]

Menard LC, et al. B cells amplify IFN-gamma production by T cells via a TNF-alpha-mediated mechanism. Journal of immunology. 2007; 179:4857-4866. doi:179/7/4857 [pii].

Mohanty S, et al. Prolonged Proinflammatory Cytokine Production in Monocytes Modulated by Interleukin 10 After Influenza Vaccination in Older Adults. The Journal of infectious diseases. 2014 doi:10.1093/infdis/jiu573.

Mueller S, et al. Differences in fecal microbiota in different European study populations in relation to age, gender, and country: a cross-sectional study. Applied and environmental microbiology. 2006; 72:1027-1033. doi:10.1128/AEM.72.2.1027-1033.2006. [PubMed: 16461645]

Mundy GR. Osteoporosis and inflammation. Nutr Rev. 2007; 65:S147-151. [PubMed: 18240539]

Murciano C, Yanez A, O'Connor JE, Gozalbo D, Gil ML. Influence of aging on murine neutrophil and macrophage function against Candida albicans. FEMS immunology and medical microbiology. 2008; 53:214-221. doi:10.1111/j.1574-695X.2008.00418.x. [PubMed: 18445021]

Neil GA, Summers RW, Cheyne BA, Carpenter C, Huang WL, Waldschmidt TJ. Analysis of Tlymphocyte subpopulations in inflammatory bowel diseases by three-color flow cytometry. Digestive diseases and sciences. 1994; 39:1900-1908. [PubMed: 8082496]

Nikolajczyk BS. B cells as under-appreciated mediators of non-auto-immune inflammatory disease. Cytokine. 2010; 50:234-242. doi:10.1016/j.cyto.2010.02.022. [PubMed: 20382544]

Nishimura S, et al. CD8+ effector T cells contribute to macrophage recruitment and adipose tissue inflammation in obesity. Nature medicine. 2009; 15:914-920. doi:10.1038/nm.1964.

Olivieri $\mathrm{F}$, et al. The $-174 \mathrm{C} / \mathrm{G}$ locus affects in vitro/in vivo IL-6 production during aging. Experimental gerontology. 2002; 37:309-314. [PubMed: 11772517] 
Olivieri F, et al. MiR-146a as marker of senescence-associated pro-inflammatory status in cells involved in vascular remodelling. Age. 2013a; 35:1157-1172. doi:10.1007/s11357-012-9440-8. [PubMed: 22692818]

Olivieri F, Rippo MR, Procopio AD, Fazioli F. Circulating inflamma-miRs in aging and age-related diseases. Frontiers in genetics. 2013b; 4:121. doi:10.3389/fgene.2013.00121. [PubMed: 23805154]

Olsson J, Wikby A, Johansson B, Lofgren S, Nilsson BO, Ferguson FG. Age-related change in peripheral blood T-lymphocyte subpopulations and cytomegalovirus infection in the very old: the Swedish longitudinal OCTO immune study. Mechanisms of ageing and development. 2000; 121:187-201. [PubMed: 11164473]

Panda A, et al. Age-associated decrease in TLR function in primary human dendritic cells predicts influenza vaccine response. Journal of immunology. 2010; 184:2518-2527. doi:10.4049/ jimmunol.0901022.

Parish ST, Wu JE, Effros RB. Modulation of T lymphocyte replicative senescence via TNF- $\{$ alpha $\}$ inhibition: role of caspase-3. Journal of immunology. 2009; 182:4237-4243. doi:10.4049/ jimmunol.0803449.

Park HL, et al. Obesity-induced chronic inflammation is associated with the reduced efficacy of influenza vaccine. Human vaccines \& immunotherapeutics. 2014; 10:1181-1186. doi:10.4161/hv. 28332. [PubMed: 24614530]

Pawelec G, et al. T cells and aging, January 2002 update. Front Biosci. 2002; 7:d1056-1183. [PubMed: 11991846]

Pawelec G, Derhovanessian E, Larbi A, Strindhall J, Wikby A. Cytomegalovirus and human immunosenescence. Reviews in medical virology. 2009; 19:47-56. doi:10.1002/rmv.598. [PubMed: 19035529]

Pinti M, et al. Circulating mitochondrial DNA increases with age and is a familiar trait: Implications for "inflamm-aging". European journal of immunology. 2014; 44:1552-1562. doi:10.1002/eji. 201343921. [PubMed: 24470107]

Po JL, Gardner EM, Anaraki F, Katsikis PD, Murasko DM. Age-associated decrease in virus-specific CD8+ T lymphocytes during primary influenza infection. Mechanisms of ageing and development. 2002; 123:1167-1181. [PubMed: 12044966]

Pozzilli $\mathrm{P}$, et al. The immune response to influenza vaccination in diabetic patients. Diabetologia. 1986; 29:850-854. [PubMed: 3569690]

Pravica V, Perrey C, Stevens A, Lee JH, Hutchinson IV. A single nucleotide polymorphism in the first intron of the human IFN-gamma gene: absolute correlation with a polymorphic CA microsatellite marker of high IFN-gamma production. Human immunology. 2000; 61:863-866. [PubMed: 11053629]

Prosch S, Staak K, Stein J, Liebenthal C, Stamminger T, Volk HD, Kruger DH. Stimulation of the human cytomegalovirus IE enhancer/promoter in HL-60 cells by TNFalpha is mediated via induction of NF-kappaB. Virology. 1995; 208:197-206. doi:10.1006/viro.1995.1143. [PubMed: 11831701]

Rajilic-Stojanovic M, Heilig HG, Molenaar D, Kajander K, Surakka A, Smidt H, de Vos WM. Development and application of the human intestinal tract chip, a phylogenetic microarray: analysis of universally conserved phylotypes in the abundant microbiota of young and elderly adults. Environmental microbiology. 2009; 11:1736-1751. doi:10.1111/j. 1462-2920.2009.01900.x. [PubMed: 19508560]

Ren Z, et al. Effect of age on susceptibility to Salmonella Typhimurium infection in C57BL/6 mice. Journal of medical microbiology. 2009; 58:1559-1567. doi:10.1099/jmm.0.013250-0. [PubMed: 19729455]

Renehan AG, Tyson M, Egger M, Heller RF, Zwahlen M. Body-mass index and incidence of cancer: a systematic review and meta-analysis of prospective observational studies. Lancet. 2008; 371:569578. doi:10.1016/S0140-6736(08)60269-X. [PubMed: 18280327]

Renshaw M, Rockwell J, Engleman C, Gewirtz A, Katz J, Sambhara S. Cutting edge: impaired Tolllike receptor expression and function in aging. Journal of immunology. 2002; 169:4697-4701.

Sarzi-Puttini P, Atzeni F, Doria A, Iaccarino L, Turiel M. Tumor necrosis factor-alpha, biologic agents and cardiovascular risk. Lupus. 2005; 14:780-784. [PubMed: 16218487] 
Saurwein-Teissl M, et al. Lack of antibody production following immunization in old age: association with CD8(+)CD28(-) T cell clonal expansions and an imbalance in the production of Th1 and Th2 cytokines. Journal of immunology. 2002; 168:5893-5899.

Sayegh CE, Quong MW, Agata Y, Murre C. E-proteins directly regulate expression of activationinduced deaminase in mature B cells. Nature immunology. 2003; 4:586-593. [PubMed: 12717431]

Schmidt D, Goronzy JJ, Weyand CM. CD4+ CD7-CD28-T cells are expanded in rheumatoid arthritis and are characterized by autoreactivity. The Journal of clinical investigation. 1996; 97:2027-2037. doi:10.1172/JCI118638. [PubMed: 8621791]

Setty AR, Curhan G, Choi HK. Obesity, waist circumference, weight change, and the risk of psoriasis in women: Nurses' Health Study II. Archives of internal medicine. 2007; 167:1670-1675. doi: 10.1001/archinte.167.15.1670. [PubMed: 17698691]

Shembade N, Ma A, Harhaj EW. Inhibition of NF-kappaB signaling by A20 through disruption of ubiquitin enzyme complexes. Science. 2010; 327:1135-1139. doi:10.1126/science.1182364. [PubMed: 20185725]

Shi Y, Yamazaki T, Okubo Y, Uehara Y, Sugane K, Agematsu K. Regulation of aged humoral immune defense against pneumococcal bacteria by IgM memory B cell. Journal of immunology. 2005; 175:3262-3267.

Shoelson SE, Lee J, Goldfine AB. Inflammation and insulin resistance. The Journal of clinical investigation. 2006; 116:1793-1801. doi:10.1172/JCI29069. [PubMed: 16823477]

Sica A, Schioppa T, Mantovani A, Allavena P. Tumour-associated macrophages are a distinct M2 polarised population promoting tumour progression: potential targets of anti-cancer therapy. European journal of cancer. 2006; 42:717-727. doi:10.1016/j.ejca.2006.01.003. [PubMed: 16520032]

Sikora E, Arendt T, Bennett M, Narita M. Impact of cellular senescence signature on ageing research. Ageing research reviews. 2011; 10:146-152. doi:10.1016/j.arr.2010.10.002. [PubMed: 20946972]

Smithey MJ, Li G, Venturi V, Davenport MP, Nikolich-Zugich J. Lifelong persistent viral infection alters the naive T cell pool, impairing CD8 T cell immunity in late life. Journal of immunology. 2012; 189:5356-5366. doi:10.4049/jimmunol.1201867.

Tchkonia T, Zhu Y, van Deursen J, Campisi J, Kirkland JL. Cellular senescence and the senescent secretory phenotype: therapeutic opportunities. The Journal of clinical investigation. 2013; 123:966-972. doi:10.1172/JCI64098. [PubMed: 23454759]

Trzonkowski P, et al. Association between cytomegalovirus infection, enhanced proinflammatory response and low level of anti-hemagglutinins during the anti-influenza vaccination--an impact of immunosenescence. Vaccine. 2003; 21:3826-3836. [PubMed: 12922116]

Vallejo AN. CD28 extinction in human T cells: altered functions and the program of T-cell senescence. Immunol Rev. 2005; 205:158-169. doi:10.1111/j.0105-2896.2005.00256.x. [PubMed: 15882352]

Vallejo AN, Weyand CM, Goronzy JJ. T-cell senescence: a culprit of immune abnormalities in chronic inflammation and persistent infection. Trends in molecular medicine. 2004; 10:119-124. doi: 10.1016/j.molmed.2004.01.002. [PubMed: 15102354]

van Duin D, et al. Prevaccine determination of the expression of costimulatory B7 molecules in activated monocytes predicts influenza vaccine responses in young and older adults. J Infect Dis. 2007a; 195:1590-1597. doi:10.1086/516788. [PubMed: 17471428]

van Duin D, et al. Age-associated defect in human TLR-1/2 function. Journal of immunology. 2007b; 178:970-975.

Wojciechowski W, et al. Cytokine-producing effector B cells regulate type 2 immunity to $\mathrm{H}$. polygyrus. Immunity. 2009; 30:421-433. [PubMed: 19249230]

Woodmansey EJ, McMurdo ME, Macfarlane GT, Macfarlane S. Comparison of compositions and metabolic activities of fecal microbiotas in young adults and in antibiotic-treated and nonantibiotic-treated elderly subjects. Applied and environmental microbiology. 2004; 70:61136122. doi:10.1128/AEM.70.10.6113-6122.2004. [PubMed: 15466557]

Zhang Q, et al. Circulating mitochondrial DAMPs cause inflammatory responses to injury. Nature. 2010; 464:104-107. doi:10.1038/nature08780. [PubMed: 20203610] 
Zhang X, Nakajima T, Goronzy JJ, Weyand CM. Tissue trafficking patterns of effector memory CD4+ $\mathrm{T}$ cells in rheumatoid arthritis. Arthritis and rheumatism. 2005; 52:3839-3849. doi:10.1002/art. 21482. [PubMed: 16329093] 


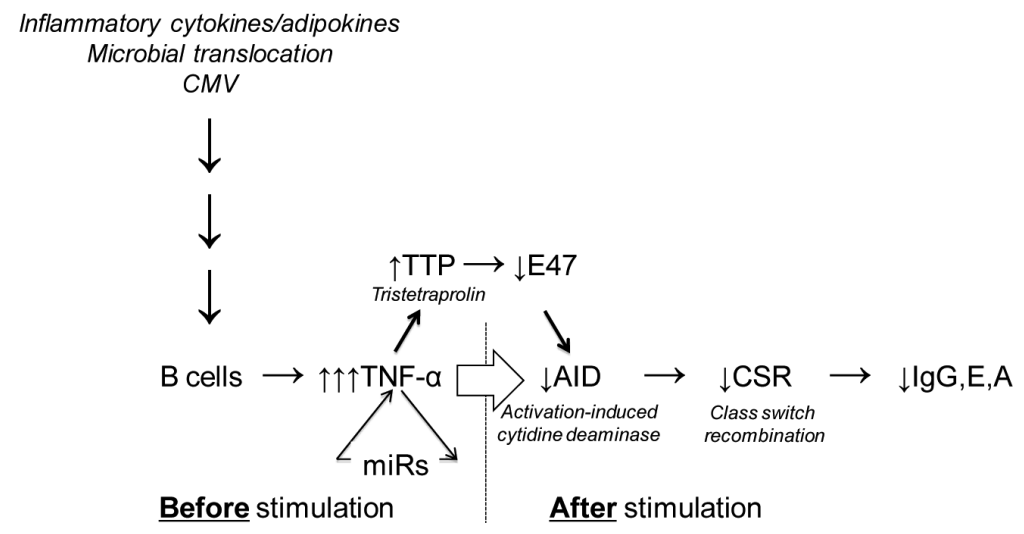

Figure 1. Molecular pathways for reduced $B$ cell responses in aging

The production of high-affinity, class-switched antibodies (IgG/E/A) is decreased both in vivo and in vitro as a consequence of reduced class switch recombination (CSR) with aging. CSR is a DNA recombination event regulated by activation-induced cytidine deaminase (AID), the enzyme responsible for opening the double stands of DNA in the S (switch) regions of Immunoglobulin genes. AID also regulates somatic hypermutation and therefore is crucial for the production of protective antibodies. AID is decreased in stimulated B cells from aged mice and humans and is transcriptionally regulated by E47, the Helix-Loop-Helix transcription factor, which is decreased in aged B cells by mRNA stability. E47 mRNA stability is down-regulated by tristetraprolin (TTP), a negative regulator of the stability of transcription factor and cytokine mRNAs. TTP is higher in unstimulated B cells from aged mice and humans, and is positively regulated by B cell intrinsic TNF-a and particular inflamma-micro-RNAs (miRs), such as miR-155 and miR-16. Levels of TTP, TNF-a and miRs in unstimulated B cells are positively regulated by serum levels of pro-inflammatory cytokines and adipokines, microbial translocation and persistent infections with viruses such as CMV. We have shown that the age-related increase in these markers is associated with TNF-a production by unstimulated B cells and that this "pre-activated" phenotype of the B cells renders them incapable of being optimally stimulated by exogenous antigens, mitogens or vaccines. 